P. SMirnov, J. MAtheW, A. NiJs, E. KAtAN, M. KARni, C. BOLM, Y. APELOIG, I. MAREK* (TECHNION-ISRAEL INSTITUTE OF TECHNOLOGY, HAIFA, ISRAEL AND RWTH AACHEN UNIVERSITY, GERMANY)

One-Pot Zinc-Promoted Asymmetric Alkynylation/Brook-Type Rearrangement/Ene-Allene Cyclization: Highly Selective Formation of Three New Bonds and Two Stereocenters in Acyclic Systems

Angew. Chem. Int. Ed. 2013, 52, 13717-13721.

\section{Tandem Enantioselective Zinc-Promoted Reaction}

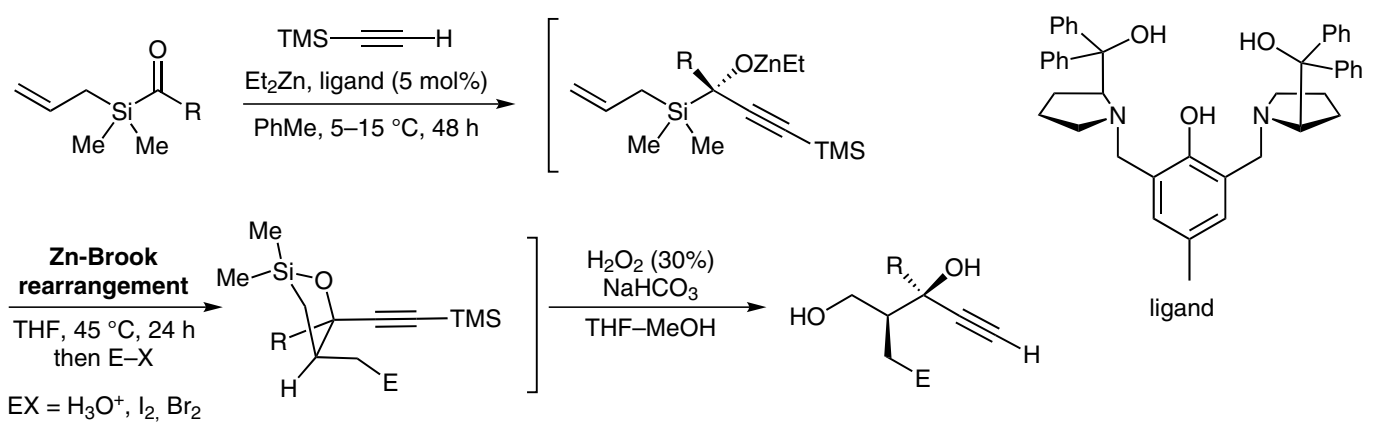

Selected examples:

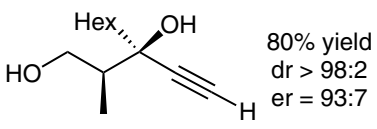<smiles>C#CC(C)(O)C(CO)CI</smiles>

$75 \%$ yield $\mathrm{dr}>98: 2$ er $=93: 7$<smiles>C#C[C@]([14CH3])(O)[C@@H](CO)CBr</smiles><smiles>C#CC(O)(CCc1ccccc1)C(C)CO</smiles>

$65 \%$ yield $\mathrm{dr}>98: 2$ er $=88: 12$

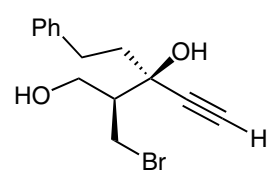

$59 \%$ yield $\mathrm{dr}>98: 2$ er $=88: 12$

Allenyl Zn-Brook rearrangement<smiles>[R15]OC([R17])(C#CC#[Y5])CC</smiles>

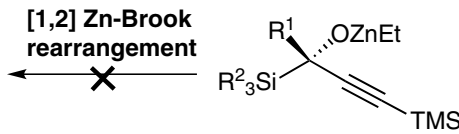

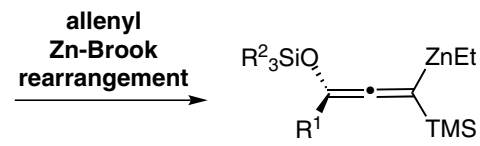

Significance: In a one-pot operation, two stereocenters and three new bonds were created with high selectivity. The reaction proceeds through a sequence of asymmetric alkynylation of an acyl silane, tandem Brook-type rearrangement, eneallene cyclization, addition of an electrophile, and finally oxidation. It will be extremely useful in organic synthesis, and it is a new approach to synthetic transformations.

\section{Category}

Metal-Catalyzed Asymmetric

Synthesis and

Stereoselective

Reactions

\section{Key words}

zinc

Brook rearrangement

alkynylation

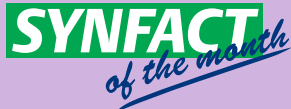

Comment: Quantum mechanical calculations show that this method passes through an allenyl Zn-Brook rearrangement and that this transformation bypasses the intermediate derived from the classic [1,2]-Brook rearrangement. This important finding nicely rationalizes the observation that the rearrangement proceeds without racemization. 